\title{
Chest Pain in a Renal Transplant Recipient due to Concomitant Cytomegalovirus and Herpes Simplex Virus Esophagitis
}

\author{
Seok Hyung Kang ${ }^{1}$, Myong Ki Baeg ${ }^{1}$, Sun-Hye Ko ${ }^{2}$, Hyunjung Hwang ${ }^{1}$, Sang Yeop $\mathrm{Yi}^{3}$, Sung Jin Moon ${ }^{4}$, Jeongkeun Park ${ }^{5}$ \\ Division of Gastroenterology, Department of Internal Medicine, International St. Mary's Hospital, Catholic Kwandong University College of \\ Medicine ${ }^{1}$, Incheon, Department of Internal Medicine, Inje University Haeundae Paik Hospital, Inje University College of Medicine ${ }^{2}$, Busan, \\ Department of Pathology, International St. Mary's Hospital, Catholic Kwandong University College of Medicine $e^{3}$, Division of Nephrology, \\ Department of Internal Medicine, International St. Mary's Hospital, Catholic Kwandong University College of Medicine ${ }^{4}$, Department of \\ Internal Medicine, International St. Mary's Hospital, Catholic Kwandong University College of Medicine ${ }^{5}$, Incheon, Korea
}

\begin{abstract}
Chest pain in kidney transplant patients is usually caused by cardiac or pulmonary problems. However, it may be rarely caused by opportunistic esophageal infections. A 66-year-old female kidney transplant recipient was admitted because of chest pain. She had been treated with high-dose steroid and immunosuppressants for acute T-cell-mediated rejection. Cardiologic and pulmonary evaluations had normal results. Endoscopic examination revealed three clear ulcerative lesions in the esophagus. Histological and immunohistochemical staining of the endoscopic biopsy specimens revealed coinfection of herpes simplex virus and cytomegalovirus. The patient was treated with intravenous ganciclovir for 2 weeks. Her symptoms completely resolved, and follow-up endoscopy revealed complete healing of the previous ulcers. Viral esophagitis should be considered in the differential diagnosis in kidney transplant recipients presenting with chest pain. (Korean J Helicobacter Up Gastrointest Res 2019;19:61-64)
\end{abstract}

Key Words: Chest pain; Cytomegalovirus; Esophagitis; Herpes simplex virus; Kidney transplantation

\section{INTRODUCTION}

The number of kidney transplantation (KT) has been increasing, due to the epidemic increase in underlying causes of end-stage renal disease such as diabetes and hypertension. ${ }^{1}$ This has led to an increase in clinicians other than nephrologists or transplant surgeons coming into contact with KT recipients, necessitating a heightened awareness of potential complications and their symptoms. Chest pain in KT recipients is usually due to cardiac or pulmonary origins, which should be ruled out as they may be life threatening. ${ }^{2-6}$ However, esophageal disorders may also cause chest pain. ${ }^{7,8}$ The most common esophageal disorder in KT recipients is esophageal candidiasis. ${ }^{9}$ Other causes of esophagitis include cytomegalovirus (CMV) or herpes simplex virus (HSV) infection. ${ }^{9}$ Because chest pain is an atypical symptom of viral esophagitis, clinicians may not consider it as a differential diagnosis.

Received: December 13, 2018 Revised: January 13, 2019 Accepted: January 14, 2019 Corresponding author: Myong Ki Baeg

Division of Gastroenterology, Department of Internal Medicine, International St. Mary's Hospital, Catholic Kwandong University College of Medicine, 25 Simgok-ro 100beon-gil, Seo-gu, Incheon 22711, Korea

Tel: +82-32-290-2895, Fax: +82-32-290-3879, E-mail: baegmk@gmail.com
We report a case of KT recipient with esophagitis caused by co-infection of CMV and HSV that presented with chest pain.

\section{CASE REPORT}

A 66-year-old female with underlying diabetes had received KT from a cadaver donor one year ago. Basiliximab 20 mg was administered on the first and fourth day after transplantation for desensitization due to human leukocyte antigen mismatch. She was diagnosed with acute T-cell mediated rejection 9 months after transplantation and had been treated with high dose steroids, tacrolimus $2.8 \mathrm{mg}$ and mycophenolate $360 \mathrm{mg}$. After one month of treatment, she was referred with chest and epigastric pain. Her vital signs were stable, breath sounds were clear, heart beats were regular without murmurs and there was no tenderness on palpation. She did not complain of dyspnea, heartburn or dysphagia but did complain of odynophagia. Cardiopulmonary evaluations were first done with the laboratory data, electrocardiogram and chest radiograph being normal. Serum CMV reverse transcription polymerase chain reaction (PCR) levels were undetectable.

Copyright $\odot 2019$ Korean College of Helicobacter and Upper Gastrointestinal Research

(ङ) The Korean Journal of Helicobacter and Upper Gastrointestinal Research is an Open-Access Journal. All articles are distributed under the terms of the Creative Commons Attribution Non-Commercial License (http://creativecommons.org/licenses/by-nc/4.0) which permits unrestricted non-commercial use, distribution, and reproduction in any medium, provided the original work is properly cited. 
Subsequent upper gastrointestinal endoscopic examination revealed three clear ulcerative lesions in the esophagus. The one at the upper esophagus was round, while those at the lower and mid esophagus were serpiginous (Fig. 1).
A biopsy was performed at each ulcer and histology revealed infiltration of inflammatory cells, intranuclear inclusions and multinucleated giant cells, suggesting HSV infection. Because hematoxylin and eosin stain was suffi-

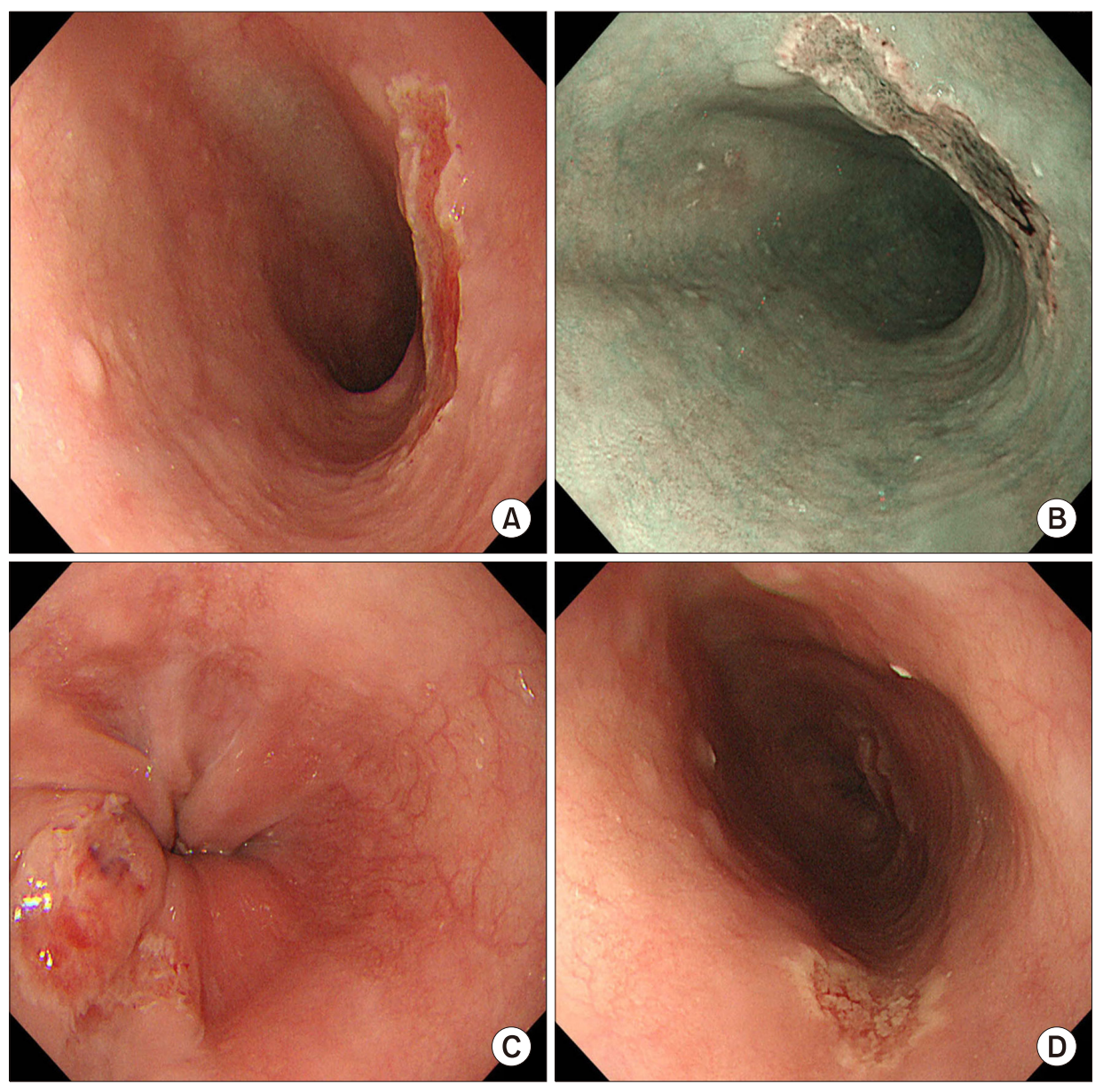

Fig. 1. Initial endoscopic findings. (A) A round-shaped ulcer is seen in the upper esophagus. (B) A narrow band image of the ulcer at the upper esophagus. (C, D) Two serpiginous ulcers are seen at the lower and mid esophagus.
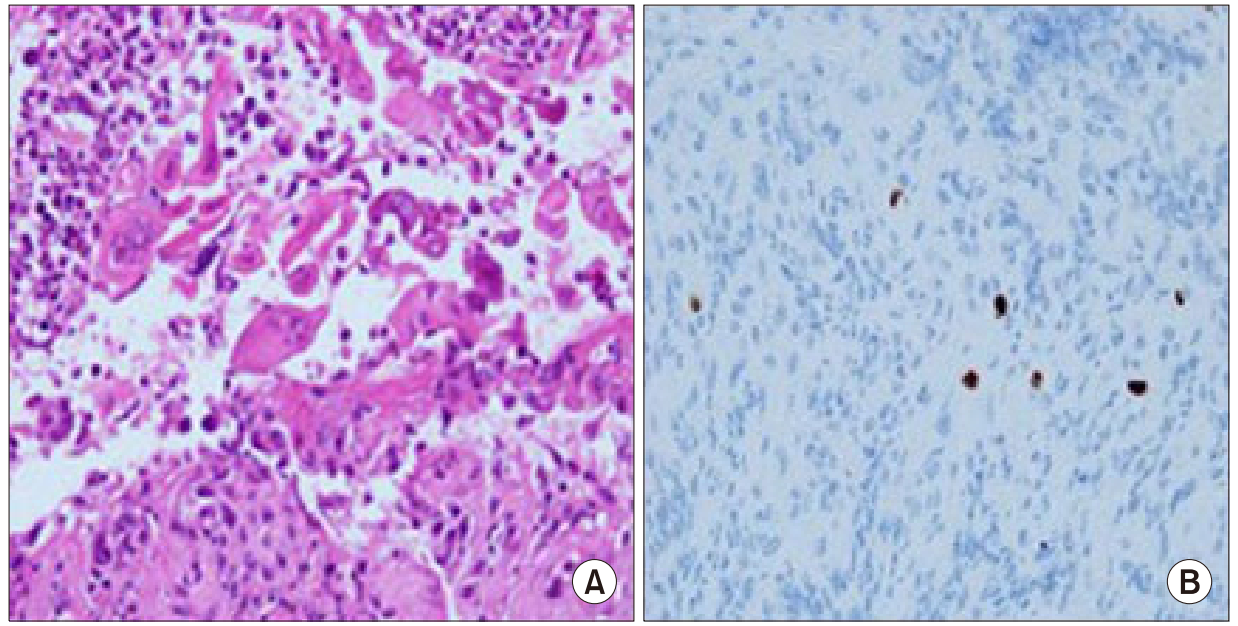

Fig. 2. Pathological findings from an esophageal biopsy. (A) Histological section showing herpes simplex virus-infected cells containing large, pink to purple intranuclear inclusions and inclusion-bearing multinucleated syncytia (H\&E, ×400). (B) Immunohistochemical staining with cytomegalovirus antibody shows some positive cells $(\times 400)$. 
cient to diagnose HSV infection, immunohistochemical staining and PCR for HSV were not performed. Immunohistochemical staining with CMV antibody showed positive results. Therefore, the pathologic results were CMV and HSV co-infection (Fig. 2). Ganciclovir was administered intravenously for 2 weeks with no side effects. Her symptoms completely resolved and follow-up endoscopy performed 2 weeks after ganciclovir treatment showed complete healing of the previous ulcers (Fig. 3).

\section{DISCUSSION}

This is a case of chest pain in a KT recipient, which was due to co-infection by CMV and HSV. This case is clinically important because chest pain in KT recipients is usually due to cardiopulmonary problems; causes of chest pain are important as they may be life-threatening. ${ }^{2-6} \mathrm{KT}$ is associated with increased risk for coronary artery disease, which is especially high in the first year after transplantation. ${ }^{2,3}$ Pulmonary complications, including pulmonary embolism, pneumothorax, and pneumonia with pleural effusion, can also cause chest pain. ${ }^{4,5}$ However, as in our case, chest pain may also be caused by viral esophagitis. Usual symptoms of viral esophagitis are difficult or painful swallowing (59\%), nausea or vomiting (42\%), abdominal pain (19\%), weight loss (25\%), fever

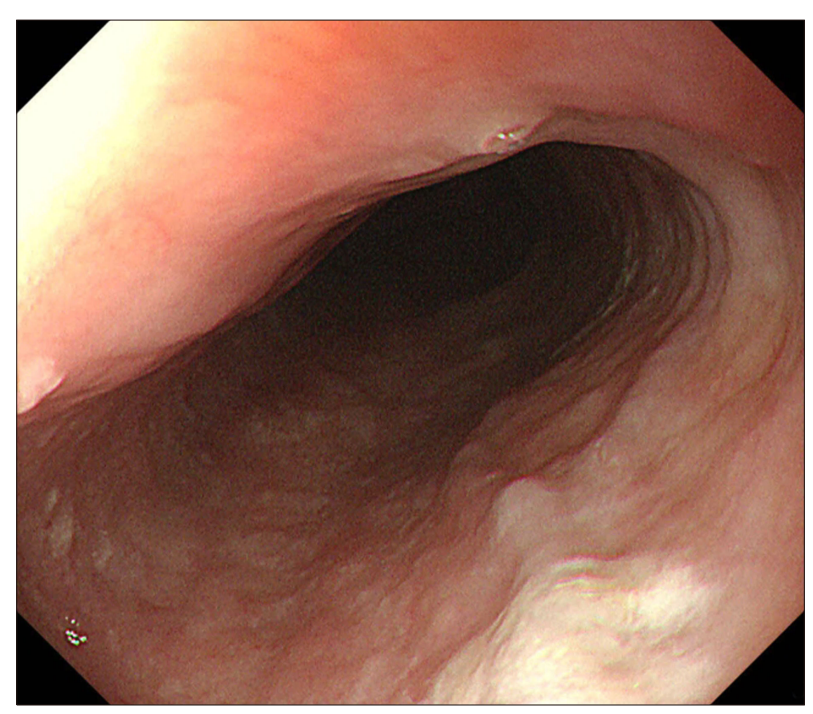

Fig. 3. Endoscopic finding after the ganciclovir treatment. The endoscopy image shows complete healing of the previous ulcers.
(20\%) and diarrhea (20\%). However, there have been several reports of viral esophagitis as a cause of chest pain in KT recipients. ${ }^{7,8}$ Therefore, we suggest that KT recipients with chest pain who have negative cardiopulmonary tests undergo upper gastrointestinal endoscopy to rule out viral esophagitis as a cause of chest pain, even in those with undetectable CMV reverse transcription PCR levels.

Esophageal co-infection in immunocompromised patients by both CMV and HSV are rare, with only few cases reported in the literature. ${ }^{10-16}$ In addition, these have been mostly reported in immunodeficiency virus infections, and rarely in KT patients. ${ }^{10-17}$ Clinicians should always consider co-infection by CMV and HSV as they have a high rate of potentially serious complications such as perforation, bleeding and death. ${ }^{10-12}$ Upper gastrointestinal endoscopy with multiple biopsies from both the ulcer base and margins are required to confirm both CMV and HSV co-infection. ${ }^{18}$ The diagnosis of HSV infectoin and CMV infection can be confirmed by biopsy, tissue culture, PCR and immunohistochemical staining. Histologic findings of the HSV infectoin are confirmed by the presence of intranuclear inclusion bodies, typical ground glass cells and multinucleated giant cells, while the CMV infection are confirmed by eosinophil intranuclear inclusions and a peripheral halo. ${ }^{18}$ In this case, HSV infection was confirmed by large, pink to purple intranuclear inclusions and inclusion-bearing multinucleated syncytia, and CMV infection was confirmed by immunohistochemical staining. As a result, diagnosis of coinfection of CMV and HSV was possible, So PCR and tissue culture were not performed. Treatment with intravenous ganciclovir should be promptly started as ganciclovir has been reported to be efficacious for both CMV and HSV. ${ }^{19,20}$

In conclusion, viral esophagitis must be considered as a differential diagnosis in KT recipients complaining of chest pain. Upper gastrointestinal endoscopy with multiple biopsies should be performed to rule out co-infection of CMV and HSV due to its potentially serious outcomes. 


\section{CONFLICT OF INTEREST}

No potential conflict of interest relevant to this article was reported.

\section{ORCID}

Seok Hyung Kang (1)https://orcid.org/0000-0003-3367-3941

Myong Ki Baeg (1)https://orcid.org/0000-0002-4807-2447

Sun-Hye Ko (1) https://orcid.org/0000-0003-3387-3986

Hyunjung Hwang (ibttps://orcid.org/0000-0003-3688-0962

Sang Yeop Yi (1)https://orcid.org/0000-0003-2875-1263

Sung Jin Moon (1) https://orcid.org/0000-0002-6276-3009

Jeongkeun Park (1)https://orcid.org/0000-0001-6455-4609

\section{REFERENCES}

1. Kim CD. Kidney transplantation. Korean J Med 2014;86: 142-151.

2. Kasiske BL, Maclean JR, Snyder JJ. Acute myocardial infarction and kidney transplantation. J Am Soc Nephrol 2006;17:900-907.

3. Stewart G, Jardine AG, Briggs JD. Ischaemic heart disease following renal transplantation. Nephrol Dial Transplant 2000; 15:269-277.

4. Tveit DP, Hypolite I, Bucci J, et al. Risk factors for hospitalizations resulting from pulmonary embolism after renal transplantation in the United States. J Nephrol 2001;14:361-368.

5. Kerns ES, Alobaidi SA, Roayaie K, Obhrai JS. Chest pain after kidney transplantation owing to pneumomediastinum: a case report. Transplant Proc 2013;45:2811-2814.

6. Aakhus S, Dahl K, Widerøe TE. Cardiovascular morbidity and risk factors in renal transplant patients. Nephrol Dial Transpl 1999;14:648-654.

7. Moustafellos P, Hadjianastasiou V, Gray D. Postural epigastric pain as a sign of CMV gastritis: a case report. Transplant Proc 2006;38:1357-1358.
8. Joo YB, Jung HS, Baeg MK, Lee WH, Lee HJ, Yang CW. Cytomegalovirus esophagitis presents as chest pain in a renal transplant recipient. Korean J Intern Med 2013;28:497-499.

9. Ponticelli C, Passerini P. Gastrointestinal complications in renal transplant recipients. Transpl Int 2005;18:643-650.

10. Albuquerque A, Cardoso H, Ribeiro A, et al. Herpes and cytomegalovirus esophagitis. Endoscopy 2012;44 Suppl 2:E242-E243.

11. Chung HH, Jang JY, Byun JM, Park SH, Kim DH, Chang YW. Upper gastrointestinal hemorrhage from esophageal ulcer caused by coinfection of herpes simplex virus and cytomegalovirus in immunocompromised patient. Korean J Helicobacter Up Gastrointest Res 2013;13:69-72.

12. Vodovnik A, Cerar A. Synchronous herpes simplex virus and cytomegalovirus esophagitis. Z Gastroenterol 2000;38:491-494.

13. Srilatha PS, Suvarna N, Gupta A, Bhat G. Esophageal ulcer in a HIV-seropositive patient co-infected by herpes simplex and cytomegalovirus. Indian J Pathol Microbiol 2011;54:219-220.

14. Connolly GM, Hawkins D, Harcourt-Webster JN, Parsons PA, Husain OA, Gazzard BG. Oesophageal symptoms, their causes, treatment, and prognosis in patients with the acquired immunodeficiency syndrome. Gut 1989;30:1033-1039.

15. Bonacini M, Young T, Laine L. The causes of esophageal symptoms in human immunodeficiency virus infection. A prospective study of 110 patients. Arch Intern Med 1991;151: 1567-1572.

16. Wilcox CM, Schwartz DA, Clark WS. Esophageal ulceration in human immunodeficiency virus infection. Causes, response to therapy, and long-term outcome. Ann Intern Med 1995;123: 143-149.

17. Kim SE, Park SJ. Giant esophageal ulcers in a patient with human immunodeficiency virus. Korean J Helicobacter Up Gastrointest Res 2017;17:228-229.

18. Kriegsmann M, Arens N, Otto M, Kriegsmann J. Practical aspects in the evaluation of infectious esophagitis. Clin Microbiol 2013;2:119.

19. Upadhyayula S, Michaels MG. Ganciclovir, foscarnet, and cidofovir: antiviral drugs not just for cytomegalovirus. J Pediatric Infect Dis Soc 2013;2:286-290.

20. Arvin A, Campadelli-Fiume G, Mocarski E, et al. Human herpesviruses: biology, therapy, and immunoprophylaxis. Cambridge: Cambridge University Press, 2007. 